\title{
MARQUES, Rodrigo Moreno ; RASLAN, Filipe; MELO, Flávia; PINHEIRO, Marta Macedo Kerr (Org.). A informação e o conhecimento sob as lentes do marxismo. Rio de Janeiro: Garamond, 2014.
}

Resenha de Gustavo Saldanha e Marco Schneider sobre o livro "A informação e o conhecimento sob as lentes do marxismo", organizado por Rodrigo Moreno Marques, Filipe Raslan, Flávia Melo e Marta Macedo Kerr Pinheiro

\author{
Marco Schneider* \\ Gustavo Saldanha **
}

É absolutamente lúcido retratar qualquer pressuposto epistemológico-histórico que define a Ciência da Informação, em sentido estrito (um campo e suas fronteiras), e os estudos informacionais (em sentido amplo, de aglomerado de linhas de reflexão sobre o fenômeno informacional), como representantes de uma teoria do conhecimento de defesa declarada do neoliberalismo, ou, ainda, uma ontologia estruturada no capital. Elementos como a origem geopolítica, o contexto histórico e os padrões de justificativa de nascimento fundamentam a condição orientada ao pleno estabelecer das forças capitalistas e do desenvolvimento da alienação de toda uma gnose voltada para a informação no âmbito do desenvolvimento de sistemas de fluxo de dados no século XX.

Os usos e abusos do "social" e da "sociedade" enquanto categorias nocionais destituídas de uma teoria forte do conhecimento, balizada no século XIX, e/ou de uma teoria crítica da cultura, de fundo frankfurtiano, no entanto, são as máculas mais prudentes para a categorização de uma ciência para informação como "ciência do capital informacional instalado", ou da "superestrutura informacional". Em outros termos, considerada a co-incidência ingênua da definição da expressão "ciência da informação", a partir de Robert Taylor, nos encontros do Instituto de Tecnologia da Georgia, em 1961, com o marco de constituição de tal episteme, não podemos compreender outra razão para tal justificativa, principalmente quando correlacionamos também a difusão desta definição pelo resto do mundo com uma vasta dominação discursivo-gnosiológica sobre as demais construções epistêmicas dedicadas à questão da informação, salvo raras exceções, como o caso do pensamento francês.

Se tomarmos uma perspectiva histórica de, no mínimo, média duração, e, ao mesmo tempo, se alteramos a rota vertical da centralidade estadunidense na definição de

\footnotetext{
* Doutor em Comunicação pela Universidade de São Paulo. Pesquisador do Ibict. Professor do Programa de Pós-Graduação em Ciência da Informação - PPGCI-Ibict/UFRJ e do Programa de Pós-Graduação em Mídia e Cotidiano - Universidade Federal Fluminense (PPGMC-UFF). Endereço: Rua Lauro Muller, $455-4^{\circ}$ andar - 22290-160 - Rio de Janeiro - RJ. Telefone : (21) 3873-9465. E-mail: marcoschneider@ibict.br.

** Doutor em Ciência da Informação pelo IBICT/UFRJ. Professor do Programa de Pós-Graduação em Ciência da Informação - PPGCI-lbict/UFRJ. Rua Lauro Muller, 455 - $4^{\circ}$ andar - 22290-160 - Rio de Janeiro RJ. Telefone : (21) 3873-9458. E-mail: gustavosaldanha@ibict.br.
} 
uma epistemologia para a informação e aceitarmos o pensamento crítico dos estudos comparados, percebemos que a perspectiva crítica se encontra presente exatamente no momento em que mais é "provocada", ou seja, o contexto da própria tentativa neoliberal de fundamentar uma ciência para informação. É o caso, por exemplo, do pensamento de Solange Puntel Mostafa, manifesto em sua tese, em 1985, mas que desde 1981 anunciava a necessidade de uma perspectiva dialética para a construção do campo que, no Brasil, passava, desde os anos 1970, a adotar a noção de "informação" como pressuposto para uma construção epistêmica radical orientada para a tecnocracia neoliberal. A principal crítica de Mostafa (1985), afastada a pura e falsa demarcação epistemológica isolada, era que pouco nos valeria discutir nossa condição como arte ou técnica ou ciência, se antes não adicionássemos a categoria do trabalho, da práxis informacional. (MOSTAFA, 1985, p. 1). A busca pelo cientificismo no campo informacional, ou apenas a luta por se chamar "ciência", era, simultaneamente, entre os anos 1960 e 1970, a fuga da realização social e socializante, alertada nos anos 1950 por Jesse Shera, no próprio contexto dos Estados Unidos.

Em estudo realizado em 2015 (anais GT 1 - XVI Enancib, no prelo), a partir de uma perspectiva articulada da Ética, da Política e da Epistemologia, interpenetradas pelo fenômeno informacional, Marco Schneider se perguntava pelos estudos do materialismo histórico e da perspectiva sócio crítica no escopo da Ciência da Informação no Brasil. Em termos mais objetivos, a pergunta era: o que lemos de Marx, Gramsci e Lukács no âmbito dos estudos 1) histórico-epistemológicos, 2) de organização e representação do conhecimento e 3) político-econômicos na Ciência da Informação brasileira? Com base no corpus analisado - a totalidade dos autores referenciados nos anais dos grupos de trabalho 1,2 e 5 de todas as edições do Enancib, bem como na categoria "todos", que envolve autor, título, resumo, texto indexado e texto completo, a partir do sistema de busca de alguns dos principais periódicos brasileiros em Ciência da Informação: Transinformação, Perspectivas em Ciência da Informação, Informação e Sociedade e Ciência da Informação, os três primeiros Qualis A1, o quarto Qualis A2 -, o estudo demonstra, pela via epistemológica, o afastamento deste "social" do escopo do pensamento dito informacional: Marx, Gramsci e Lukács são termos praticamente inexistentes entre nós.

É neste cenário que surge a centralidade e a originalidade da obra "A informação e o conhecimento sob as lentes do marxismo", organizada por Rodrigo Moreno Marques, Filipe Raslan, Flávia Melo e Marta Macedo Kerr Pinheiro, obra lançada pela editora Garamond, em 2014. ${ }^{1}$

\footnotetext{
${ }^{1}$ Rodrigo Moreno Marques, doutor e mestre em Ciência da Informação pelo Programa de Pós-graduação em Ciência da Informação da Escola de Ciência da Informação da UFMG, é autor da tese vencedora do Prêmio ANCIB de Teses 2015, defendida em 2014, intitulada "Intelecto geral e polarização do conhecimento na era da informação: o vale do silício como exemplo". Atualmente Rodrigo é professor nos cursos de graduação e pós-graduação Stricto Sensu da Universidade FUMEC e no Centro Universitário Estácio em Belo Horizonte (MG). Filipe Raslan é professor do Centro Federal de Educação Tecnológica de Minas Gerais - CEFET-MG. Possui mestrado em Sociologia pela Universidade Estadual de Campinas (2007) e doutorado em Sociologia na Universidade Estadual de Campinas (2014). Flávia Melo, a terceira organizadora, é mestre em Ciência da Informação pela UFMG e bacharel em Biblioteconomia pela mesma universidade; é também bibliotecária da Prefeitura Municipal de Belo Horizonte, Minas Gerais. Marta Macedo Kerr Pinheiro possui graduação em Letras pela Universidade Federal de Minas Gerais (1974), mestrado em Ciências da Informação pela Universidade Federal de Minas Gerais (1993), doutorado em Ciência da Informação - IBICT/CNPq-ECO-UFRJ (2001) e doutorado em Sociologie (Sanduiche) - Centre d'Études des Mouvements Sociaux (1999). A organizadora do livro realizou estágio
} 
Mais do que o resultado das reflexões empreendidas no livro publicado no ano passado, registra-se aqui a relevância histórica do "movimento" que o concebe, a saber, a realização do seminário, que emprestou seu nome à publicação, ocorrido entre 23 e 24 de novembro de 2011, na Escola de Ciência da Informação (ECl) da Universidade Federal de Minas Gerais, em Belo Horizonte. O livro foi financiado pelo PPGCI-UFMG, pela FAPEMIG e pela CAPES, além da própria ECI. Tal "movimento" ilumina uma longa tradição de busca pelo ponto de vista crítico do papel das tecnologias da linguagem na contemporaneidade, na denúncia dos novos instrumentais de alienação e das possibilidades de contracultura nos territórios discursivos colonizados por manobras informacionais. Como lembra Mostafa (1985, p. 10), a tradição mineira, ou "grupo de Minas", representava, nos anos 1970, a busca pelo cientificismo que caracteriza, no escopo do pensamento informacional propagado pelos estadunidenses, o esvaziamento da reflexão crítica. Mostafa (1985, p. 11), afirmava, sem círculos: "Não é de admirar a posição dos teóricos brasileiros, pois ela é a expressão, em larga medida, daquilo que pensam os teóricos americanos."

Mostafa (1985) recuperava o pensamento de Shera, para lembrar que era clara a demarcação da necessidade de consideração da tecnologia como um meio, e não um fim, e da questão social do trabalho no campo informacional como o foco, e não a circunstância. O resultado, no entanto, é o contrário. O campo, a partir dos Estados Unidos, aprofunda-se no que Mostafa (1985, p. 15) denomina como "Liberalismo Cientificista". Tal expressão, reportando-se ao materialismo histórico, esclarece a pensadora, resultava na condição de que é "liberal qualquer posição que ignora a divisão social do trabalho como sendo uma divisão histórica, produzida, tomando-a como natural".

A apresentação da obra, realizada por Marques e Raslam, deixa clara a intenção geral deste "movimento" anti-naturalização das práticas informacionais: se as novas redes sócio técnicas multiplicam o uso de categorias como informação e conhecimento, contribuem diretamente pela destituição tanto de um valor epistêmico quanto de um valor sociológico para tais construtos conceituais. O resultado é a elaboração absolutamente inócua de expressões como "sociedade da informação e do conhecimento", "capital intelectual" e "economia do conhecimento", tornadas florilégios publicitários para venda de computadores pessoais a partir dos anos 1980 e aparelhos móveis de telefonia nas últimas décadas, bem como para a comercialização das terras em comodato do acesso à rede (o latifúndio líquido dos conectados em tempo integral contra a massa sem-teto digital, ora sem hardware, ora sem software, ora sem conexão). O quadro das contradições imersas nestas categorias solúveis pode ser considerado o grande leit motiv da obra.

Destaca-se em "A informação sob as lentes do marxismo" a relação direta entre autores de um pensamento "institucionalmente informacional", ou seja, docentes e pesquisadores partícipes geopoliticamente de instituições de Ciência da Informação, e autores advindos de outras searas institucionais acadêmicas. Vale destacar a presença de Marcos Dantas (UFRJ), Alain Hercovivci (UFES) e César Bolaño (UFS), teóricos fundadores e atores diretos da União Latina de Economia Política da Informação, da Comunicação e da Cultura (Ulepicc), associação científica que tem na

pós-doutoral em Ciência da Informação e da Comunicação pela Universidade Paul Sabatier/IUT/Toulouse III (2008). Atualmente Marta Kerr é professora permanente da Universidade FUMEC e professora colaborador do Programa de pós-Graduação em Ciência da Informação da Universidade Federal de Minas Gerais. 
fortuna teórica inspirada na obra de Marx, junto a outras correntes do pensamento crítico, sua principal referência.

Com Eleutério Prado, em "Intelecto geral", recuperando no Grundisse de Marx as perspectivas críticas para um olhar sobre a técnica e o intelecto, podemos compreender que as mudanças advindas no modo de vida de um capitalismo imerso no drama informacional, atualmente se resumem no advento e generalização das máquinas computacionais e dos ciclópicos sistemas de comunicação que são dependentes delas, assim como podemos afirmar a existência de uma interdependência alienante e vigilante de tais máquinas e seus agentes. O resultado, como alerta Prado, é a transformação cada vez mais intensa de trabalhadores como supervisores e regulares da produção. Marcos Dantas, por sua vez, em "As rendas informacionais e a apropriação capitalista do trabalho científico e artístico", atualiza o debate em torno da teoria do Valor, de Marx, ao mesmo tempo em que atinge um ponto nevrálgico dos estudos informacionais: os artefatos do contexto informacional são neguentrópicos, sendo a neguentropia o oposto de entropia. Esta, nos termos do autor, "vem a ser a medida da perda da capacidade contida em um corpo para fornecer trabalho", enquanto a primeira é "a medida da capacidade de fornecer trabalho" (p. 38) O consumo de um bife é entrópico, pois sua energia é dissolvida ou transferida no ato de consumo; a leitura de um livro é neguentrópica, pois o livro permanece praticamente igual ao que era antes da leitura, mesmo tendo fornecido trabalho, provocado alterações em nossos neurônios, em nossa cognição. O pano de fundo neguentrópico se constitui assim como a marca de um plano reflexivo, de certo modo antecipado por Marx, na visão de Dantas, em diálogo direto com Eleutério Prado, que conduz (nos leva) ao estado de produção-regulação do processo produtivo por parte do trabalho. Alerta-nos Marcos Dantas, no entanto, que esta condição é, ao mesmo tempo, vítima de sua centralidade: forças contrariantes, principalmente no mundo artístico, intervém no mundo produtivo, abrindo mão de formas pré-determinadas de condicionantes de renda, como direitos autorais. Isto não reduz o modo crítico de perceber a racionalidade capitalista, pois ela continua, em sua visão, negando os fundamentos da mercadoria e expandindo a apropriação de rendas informacionais.

Rosilene Horta Tavares adentra a discussão, tantas vezes marginal nos estudos informacionais, das multiplicações de hegemonias a partir do uso das tecnologias contemporâneas, tendo como solo empírico o contexto da pedagogia escolar. A partir de uma aproximação ao pensamento da Escola de Frankfurt, em "Tecnologias da informação e comunicação: a lógica instrumental do acesso", Tavares demonstra que, na atualidade, o capitalismo se realiza no mundo pedagógico como força de produção de hábitos de consumo midiatizados. Em outras palavras, o modo de avanço da Internet dentro de um contexto capitalista resulta objetivamente em uma aproximação tentacular aos tradicionais desempenhos alienadores de instrumentos como televisão, cinema e rádio.

Alain Herscovici propõe uma tentativa de definição do "capitalismo imaterial", indagando-se sobre os potenciais marxianos de delineamento de tal noção, bem como registrando a necessidade de elaboração de distintas ferramentas analíticas para fenômenos socioeconômicos da atualidade condicionada pelo contexto informacional, como o fenômeno da chamada Economia Criativa. Assim como Tavares, Herscovici se aproxima da corrente frankfurtiana para demonstrar que os elementos singulares inerentes aos bens culturais e imateriais, afastados da tradicional crítica marxiana da economia, generalizaram-se para as demais atividades econômicas, demarcando uma nova fase do capitalismo, tratada como imaterial. Em 
"Trabalho, capital intangível e historicidade do valor: uma tentativa de definição do capitalismo imaterial", Herscovici lembra que esta fase se caracteriza pela valorização aleatória, ausência de relação entre custos e preços, como também ausência de preços reguladores e da dimensão especulativa.

Michael Perelman, em "Propriedade intelectual e a forma de mercadoria: novas dimensões na transferência legislada da mais-valia", debate um aspecto central presente nas discussões finais de Marcos Dantas, relativo aos "novos modelos de negócio" do capitalismo. Perelman aborda um elemento que integra as linhas de justificação epistemológica dos estudos informacionais, ou seja, a produção em ciência e tecnologia, destacando o uso generalizado da propriedade intelectual neste território. Seu pensamento visa demonstrar como os direitos de propriedade intelectual, fundados em uma ótica do capital, obstruem a natureza da livre pesquisa científica, permitindo com que grandes descobertas em C\&T fiquem retidas ou limitadas ao julgo de grandes empresas.

César Bolaño e José Guilherme da Cunha Castro Filho aprofundam o ponto de vista da crítica materialista-histórica, demonstrando como o desenvolvimento técnicoinformacional intensifica a subsunção do trabalho, especificamente do trabalho intelectual. A unidade para comprovar tal condição é o modo de produção dos softwares. Em "Os limites à taylorização do trabalho na fase de concepção da produção de software", os autores mostram que se pode comparar, em certo sentido, a produção dos chamados aplicativos ao modelo econômico de produção de Taylor, uma vez que a autonomia do trabalhador é igualmente retirada, tendo como mudança apenas a aproximação-distanciamento à ferramenta. A padronização do uso, no entanto, condiciona a alienação do trabalhador, fundando a subjunção formal do trabalho intelectual.

Com Hormindo Pereira de Souza Júnior, em "Acerca da perspectiva ontológica que matriza a teoria social marxiana e a produção e reprodução social dos conhecimentos", encontramos o enquadramento de uma ontologia social, ou ontologia do ser social, baseada na relação entre homem e natureza e estruturada no ato de produzir. Souza Júnior insiste na demonstração de como a ontologia marxiana buscava centralmente afastar a especulação e a demarcação de subjetivismos em uma fundamentação do homem, conduzindo o discurso dos universais para o mundo da produção, reprodução e distribuição de conhecimentos. Em outras palavras, tal ontologia é estruturada em uma historicidade material, sob e sobre a qual toda e qualquer epistemologia se edifica. Esta teoria do conhecimento, porém, se vê absolutamente violada por fenômenos socioeconômicos imersos na estrutura e na superestrutura, fantasiados como condições naturais e não históricas, como é o caso do tempo. É aqui que Henrique Amorim argumenta, por sua vez, na reflexão "Tempo de trabalho e luta de classes", a posição marxiana de construção da relação entre tempo e trabalho como processo de exploração da classe trabalhadora. Dialogando com os outros autores que se apropriam do Grundisse, Amorim trata a fase atual do capitalismo, chamada "pós-grande indústria", não como abertura ou estruturação de uma autorruptura. Em seu ponto de vista, a classe trabalhadora, no contexto informacional, se viu imersa na enorme e tentacular capacidade de recomposição abrupta de bases de dominação e de exploração do capitalismo. Amorim aponta exemplos objetivos desta veloz reorganização do capital, como perda de direitos trabalhistas, terceirização e precarização do trabalho, além de codificação das formas de trabalho intelectual.

Maria Guiomar da Cunha Frota toma a direção de uma interpretação marxiana dos movimentos sociais no mundo contemporâneo. Tendo como objeto de análise do 
Movimento Ocupe Wall Street nos Estados Unidos e o Movimento pela Educação Pública no Chile, e ancorando-se analiticamente no 18 de Brumário e em A Luta de Classes na França, a autora, em "Movimentos sociais contemporâneos sob as lentes do marxismo", enfatiza a necessidade de diálogo com as categorias analíticas elaboradas por Marx. Frota aponta que o movimento constituído na América do Sul obteve mais êxito na construção da opinião pública, sendo capaz de tecer dimensões defensivas, ou seja, comunicativas, e ofensivas, isto é, estratégicas, diferentemente do movimento Ocupe Wall Street, mais circunscrito no âmbito defensivo. A autora procura enfatizar a necessidade de uma perspectiva interpretativa dos movimentos sociais pela via do conceito de práxis e da centralidade da categoria de transformação social, demonstrando a relevância histórica das ações coletivas fundadas na sociedade civil.

Remontando a construção epistemológica no século XX, Carlos Alberto Ávila Araújo procura compreender as fundações e as influências do pensamento marxiano no desenvolvimento da Arquivologia, da Biblioteconomia, da Museologia e da Ciência da Informação. Reconstruindo o discurso histórico de formação e delineamento de tais epistemes, Araújo destaca a relação de aproximação às abordagens marxianas no tempo-espaço de suas historicidades, apesar da condicionante tecnicista e histórica de tais áreas, demonstrando que, na contemporaneidade, pode-se encontrar uma relação mais direta e um quadro de tendências de aprofundamento crítico nestes saberes, principalmente a partir de abordagens socioculturais nos estudos informacionais, dedicadas à compreensão de sujeitos e na identificação de instituições (museus, arquivos e bibliotecas) como fenômenos socialmente construídos. Verticalizando esta reflexão, Alcenir Soares dos Reis demonstra, em "Informação e educação no contexto da ECI UFMG: interlocuções históricas e contrapontos", a construção da perspectiva sócio crítica dentro da Escola de Ciência da Informação, a partir da linha de pesquisa atualmente denominada "Informação, Cultura e Sociedade", que atravessou, com alterações, os cursos de Mestrado em Biblioteconomia | Administração de Bibliotecas e Mestrado em Ciência da Informação. Reis sublinha as ações balizadas em abordagens aplicadas, como o Programa Carro-Biblioteca, iniciado em 1975, e aquelas de fundo téorico-discursivo, comprovadas nas teses e dissertações defendidas sob a fundamentação teóricosociológica, sendo duas delas, de Ana Amélia Lage Martins e Renata Moutinho Vilela, premiadas pela Associação Nacional de Pesquisa e Pós-Graduação em Ciência da Informação (ANCIB). A autora destaca, por fim, o papel de resistência e crítica às condicionantes do capitalismo e às visões reformistas (e não revolucionárias), desempenhado pela linha de pesquisa no contexto da Pós-Graduação em Ciência da Informação da UFMG.

Concluindo com um mergulho direto na construção de uma escola para uma certa ciência da informação, como visto em Reis, podemos inferir, com a obra, que o devir tecnológico de uma ciência para a informação caracterizou-se por uma profunda divisão de classes, entre os informa(tiza)dos e os não informa(tiza)dos. Resulta daí uma ampla depreciação das atividades não informacionais. A valorização de práticas informacionais é fonte direta para a construção de uma gama de novos preconceitos profissionais. Retomando Mostafa (1985, p. 24-25), como nos alertava Álvaro Vieira Pinto, o "trabalho é sempre científico", incluindo o do lixeiro. O processo de tecnologização deste trabalho é que lhe conferirá um falso status de "científico". Não nos parece ser duvidosa a condição de que a "informação", no século XX e no princípio do XXI, instaura-se como elemento de divisão de classes e, principalmente, nova arma de hierarquização epistêmica e subordinação pela alienação. 


\section{REFERÊNCIAS}

MARQUES, Rodrigo Moreno. A informação e o conhecimento sob as lentes do marxismo. Rio de Janeiro: Garamond, 2014.

MOSTAFA, Solange Puntel. Epistemologia da Biblioteconomia. 1985. 147 f. Tese (Doutorado). Pontifícia Universidade Católica de São Paulo, São Paulo, 1985. 